\title{
Preparation of Transdermal Patch from Propranolol Base Prepared from Hydrochloric Salt and Evaluation of its Physical Parameters
}

\author{
Vishal N. Kushare \\ Professor, N.D.M.V.P.S Institute of Pharmaceutical Sciences, \\ Adgaon, Nashik, Maharashtra, India
}

\begin{abstract}
Propranolol is a beta-blocker.3 Beta-blockers affect the heart and circulation (blood flow through arteries and veins). Propranolol is a nonselective betaadrenergic receptor blocker (beta-blocker) that is widely used for the therapy of hypertension, cardiac arrhythmias, angina pectoris and hyperthyroidism. Propranolol has yet to be convincingly associated with clinically apparent liver injury and is often used in patients with liver disease and cirrhosis. Traditional medication delivery methods, such as pills, capsules, liquids, powders, and intravenous needles, are often inefficient or invasive and can lead to undesirable side effects8. A transdermal patch is a medicated adhesive patch that is placed on the skin to deliver a specific dose of medication through the skin and into the bloodstream. Often, this promotes healing to an injured area of the body. The present study of preparation of Propranolol base from hydrochloric salt, which results white amorphous powder of Propranolol base and characterization of different parameters is done for its physiochemical properties. Also preparation of monolithic Transdermal patch from Propranolol hydrochloride and evaluation of different physical parameters.
\end{abstract}

Keywords: Propranolol Hydrochloride, Solubility, Spectroscopic analysis, Transdermal Patch, Skin, Permeation.

\section{INTRODUCTION:}

Propranolol is used to treat tremors, angina (chest pain), hypertension ${ }^{8}$ (high blood pressure), heart rhythm disorders, and other heart or circulatory conditions. It is also used to treat or prevent heart attack, and to reduce the severity and frequency of migraine headaches.
Propranolol Hydrochloride is the hydrochloride form of propranolol, a synthetic beta-adrenergic receptor blocker with antianginal, antiarrhythmic, and antihypertensive properties. Propranolol competitively antagonizes beta-adrenergic receptors, thereby inhibiting beta-adrenergic reactions, such as vasodilation, and negative chronotropic and inotropic effects.

Transdermal patches are simple to use and constitute a simple albeit efficient idea for medication delivery. One side of the patch contains the medication, which is formulated into the skin contact adhesive. It is this side of the patch which is adhered to the skin. A person's skin is his or her largest organ. It covers and protects the body, regenerates when needed, and provides limited but essential permeation.

Drug delivery is the method or process of administering a pharmaceutical compound to achieve a therapeutic effect in humans or animals. Drug delivery technologies are patent protected formulation technologies that modify drug release profile, absorption, distribution and elimination for the benefit of improving product efficacy and safety, as well as patient convenience and compliance ${ }^{1}$.

The skin has three layers. The first layer is called the epidermis. The second layer of the skin is called the dermis. It lies beneath the epidermis and contains connective tissue that gives the skin structure and strength. This layer of skin transmits medication from a patch into the deepest layer named as Hypodermis which contains blood vessels which also reach into the dermis and epidermis. These blood vessels are important in the transmission of medication from a patch to the bloodstream. 


\section{In vitro drug permeation study:-}

In vitro study was carried out to predict the delivery and permeation of the drug molecule through the skin surface in the body of the living animal. This was achieved by using a Franz diffusion cell.

\section{$>$ Preparation of rat abdominal skin:-}

The male wistar rats weighing 170-190 g were sacrificed using anesthetic ether. The full thickness skin was removed from the abdominal region and abdominal hairs were removed by depilatory. The dermal side of the skin was washed thoroughly with distilled water to remove the blood vessels and adhering tissues. The skin of the test animal was then wrapped in aluminum foil and stored in freezer until further use. Prior to the experiment the skin was equilibrated for 15 minutes in the dissolution medium (phosphate buffer $\mathrm{pH}$ 7.4).

\section{EXPERIMENTAL WORK}

Preparation of Propranolol free base from official salt form:-

Firstly we prepared Propranolol base from hydrochloric salt. In $25 \mathrm{ml}$ of distilled water, $1 \mathrm{gm}$ of Propranolol hydrochloride was dissolved. Addition of Strong ammonia solution and $\mathrm{pH}$ was adjusted upto 9.4, and then Propranolol free base was precipitated out. Extraction and purification of base using solvent ether. Four times, the Extraction process was carried out using $25 \mathrm{ml}$ ether. Ethereal phase was collected and evaporated at $60^{\circ} \mathrm{C}$. White amorphous powder of Propranolol base was obtained.

\section{A. Characterization Parameters:-}

The physiochemical properties of Propranolol free base were determined using following Parameters

\section{Determination of Melting point:-}

Determination of melting point of drug was done by taking small amount of drug in a capillary tube closed at one end and placed in a melting point apparatus and the temperature at which drug melts was recorded. This was performed in triplicates and average value was noted.

\section{$>\quad$ Determination of partition co-efficient:-}

Using n-octanol as oily phase and phosphate buffer, $\mathrm{pH} 7.4$, as aqueous phase, the partition co-efficient study was performed. The two phases were mixed in an equal quantity and were saturated with each other on a mechanical water bath shaker NSW-133 at $34^{\circ} \mathrm{C}$ for $18 \mathrm{hr}$. The saturated phases were separated by centrifugation at $2000 \mathrm{rpm}$ on a REMI R-23 centrifuge. Standard plots of drug were prepared for both, the phosphate buffer and octanol. Equal volumes $(12.5 \mathrm{ml}$ each) of the two phases were taken in conical flasks and, to each; 100mg of weighed amount of drug was added. The flasks were shaken at $34^{\circ} \mathrm{C}$ for $6 \mathrm{hr}$ to achieve a complete partitioning at 100rpm. The two phases were separated by centrifugation at $1000 \mathrm{rpm}$ for $5 \mathrm{~min}$ and they were then analyzed for respective drug contents by UV/VIS spectroscopy method. The partition co- efficient of drug $\mathrm{K} \mathrm{o} / \mathrm{w}$ was calculated using the following formula:

$\mathrm{K} \mathrm{o} / \mathrm{w}=($ Concentration in octanol/ Concentration in phosphate buffer $\mathrm{pH}$ 7.4)

\section{Solubility studies:-}

In phosphate buffer solution, $\mathrm{pH} 7.4$, the solubility study of Propranolol base was performed in distilled water, methanol, chloroform, ether, alcohol (95\%), acetone, toluene, glycerol, liquid paraffin, triethanol amine and silicone oil separately by adding excess amounts of drug in each case and keeping the excess drug containing flasks on a water bath shaker NSW133 for $18 \mathrm{hr}$ at $34^{\circ} \mathrm{C}$.

\section{UV/VIS Spectroscopic Analysis:-}

UV spectrum of Propranolol base was recorded on UV/VIS Spectrophotometer by scanning $5 \mu \mathrm{g} / \mathrm{ml}$ solution of Propranolol base in $0.01 \mathrm{~N}$ hydrochloric acid and scanned between 200-400nm using UV/VIS Spectophotometer.

\section{Infrared (IR) Spectroscopic Analysis:-}

Using potassium bromide (KBr) pellet method, Fourier Infrared (FTIR) spectrums of moisture free samples of Propranolol base was recorded on IR spectrophotometer. The scanning range was $4000-$ $400 \mathrm{~cm}^{-1}$ and the resolution was $1 \mathrm{~cm}^{-1}$.

\section{$>$ Differential Scanning Calorimetry (DSC) Analysis:-}

DSC scans of the powered samples were recorded using DSC- Shimadzu 60 with TDA trend line software. Drug was weighed (7-10 mg) and heated at a scanning rate of $10^{\circ} \mathrm{C} / \mathrm{min}$ under dry nitrogen flow $\left(100 \mathrm{ml} / \mathrm{min}\right.$ ) between $50-350^{\circ} \mathrm{C}$. Aluminium pans and lids were used for drug sample. Pure water and indium were used to calibrate the DSC temperature scale and enthalpy response. 


\section{PROCEDURE}

The receptor compartment of the Franz diffusion cell was filled with $65 \mathrm{ml}$ of phosphate buffer $\mathrm{pH}$ 7.4. The contents of the diffusion cell were stirred using a teflon coated bead at a constant speed of $50 \mathrm{rpm}$ on a magnetic stirrer. The isolated rat skin was mounted on the diffusion cell and the transdermal patch was placed over the skin. The temperature of the medium in the receiver compartment was maintained at $37 \pm$ $1^{\circ} \mathrm{C}$ with the water jacket. The donor compartment was kept open to maintain the exposure of system to ambient conditions. The amount of drug permeated in the receptor solution was determined by withdrawing $1 \mathrm{ml}$ at hourly intervals. Each time equal volume of buffer was supplemented in the receptor compartment to maintain sink condition. The samples were then diluted to $10 \mathrm{ml}$ and analyzed for drug content at 236 $\mathrm{nm}$ using UV spectrophotometer. The permeation study was carried out for 11 hours.

\section{RESULTS}

Propranolol base prepared form hydrochloric salt was white amorphous powder, which showed following characteristics:

\section{$>$ Melting point:-}

Melting point of Propranolol base was determined by capillary tube method and it was found to be $162^{\circ}$ $\mathrm{C} \pm 1.502$ (average of three readings). This value is same as that of the literature citation. ${ }^{3}$

\section{$>$ Partition co-efficient:-}

Octanol and in vitro study fluid (here phosphate buffer, $\mathrm{pH}$ 7.4) are considered to be the standard system to determine drug partition coefficient between skin and in vitro study fluid. The logarithmic value of partition coefficient $(\log P)$ value was experimentally found to be 2.186 . The results obtained also indicate that the drug possess sufficient lipophillicity, which fulfills the requirements of formulating it into a transdermal patch. Partition coefficient should be in the range of 1 to 4 .

\section{Solubility study:-}

Solubility of Propranolol base was evaluated in different solvent.

\begin{tabular}{|c|c|}
\hline Solvent & Solubility \\
\hline Phosphate buffer (pH 7.4) & Insoluble \\
\hline Methanol Develon & Freely soluble \\
\hline Chloroform & Freely soluble \\
\hline Alcohol $(95 \%)$ & Freely soluble \\
\hline Acetone & Freely soluble \\
\hline Silicone oil & Insoluble \\
\hline $0.01 \mathrm{~N}$ Hydrochloric acid & Soluble \\
\hline Distilled water & Insoluble \\
\hline Liquid paraffin & Soluble $<$ \\
\hline Triethanolamine & Soluble \\
\hline Ether & Freely soluble \\
\hline Toluene & Freely soluble \\
\hline Glycerol & Insoluble \\
\hline
\end{tabular}

An attempt was made at this point to learn whether the media phosphate buffer, $\mathrm{pH} 7.4$, was able to maintain sink condition in diffusion as well as in permeation studies. Here form solubility studied data it was found that solubility of drug was poor in phosphate buffer, $\mathrm{pH}$ 7.4. Therefore it becomes difficult to maintain sink condition during diffusion study. Propranolol base was soluble in $0.01 \mathrm{~N} \mathrm{HCl}$ and it was selected as a diffusion medium.

\section{UV/VIS Spectroscopic analysis:-}

The UV maxima of resultant solution were measured with Shimadzu, Japan UV/VIS Spectophotometer. The UV maxima of Propranolol base in the solution was found to be $236.0 \mathrm{~nm}$, which was suitable for the preparation of standard curve and estimation of Propranolol base from various formulations. Figure shows the UV spectrograph of Propranolol base in 0.01N HCL. 


\section{UV Spectrograph}

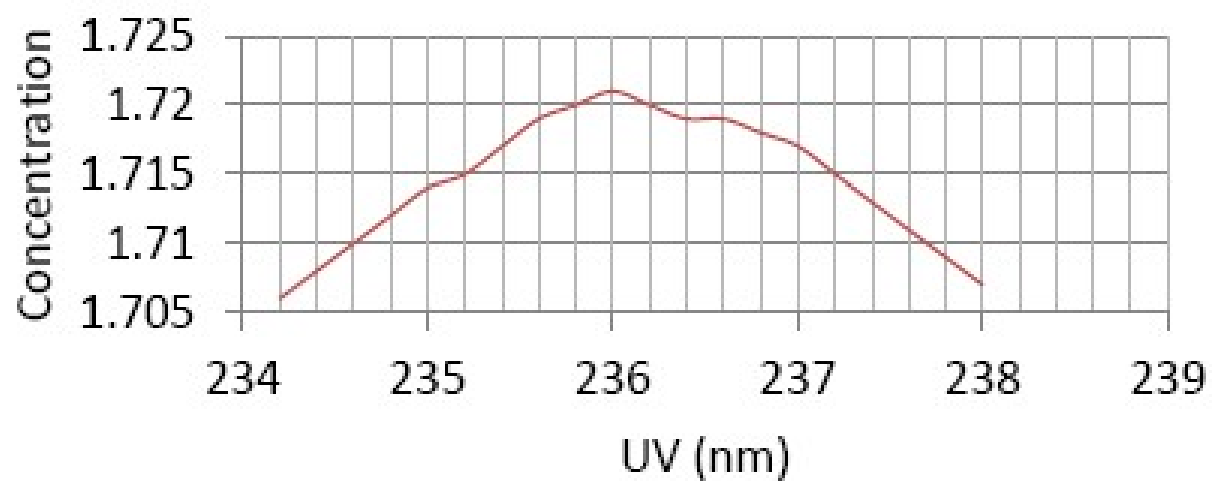

\begin{tabular}{|c|c|c|c|c|c|c|c|c|}
\hline $\begin{array}{c}\text { Sr. } \\
\text { No. }\end{array}$ & $\begin{array}{c}\text { UV } \\
(\mathbf{n m})\end{array}$ & Concentration & $\begin{array}{c}\text { Sr. } \\
\text { No. }\end{array}$ & $\begin{array}{c}\text { UV } \\
(\mathbf{n m})\end{array}$ & Concentration & $\begin{array}{c}\text { Sr. } \\
\text { No. }\end{array}$ & $\begin{array}{c}\text { UV } \\
(\mathbf{n m})\end{array}$ & Concentration \\
\hline 1 & 238 & 1.707 & 8 & 236.6 & 1.719 & 15 & 235.2 & 1.715 \\
\hline 2 & 237.8 & 1.709 & 9 & 236.4 & 1.719 & 16 & 235 & 1.714 \\
\hline 3 & 237.6 & 1.711 & 10 & 236.2 & 1.72 & 17 & 234.8 & 1.712 \\
\hline 4 & 237.4 & 1.713 & 11 & 236 & 1.721 & 18 & 234.6 & 1.71 \\
\hline 5 & 237.2 & 1.715 & 12 & 235.8 & 1.72 & 19 & 234.4 & 1.708 \\
\hline 6 & 237 & 1.717 & 13 & 235.6 & 1.719 & 20 & 234.2 & 1.706 \\
\hline 7 & 236.8 & 1.718 & 14 & 235.4 & 1.717 & & & \\
\hline
\end{tabular}

\section{$>$ Infrared (IR) Spectroscopic Analysis}

Propranolol was subjected for FTIR spectroscopic analysis, to characterize drug. FTIR Spectra for base was compared with that given for FTIR spectra of official salt form. Diagnostic peaks and finger print regions were identical. These characteristics peaks are useful in drug excipients compatibility study.

Fig: FT-IR Spectra of pure drug (Propranolol)

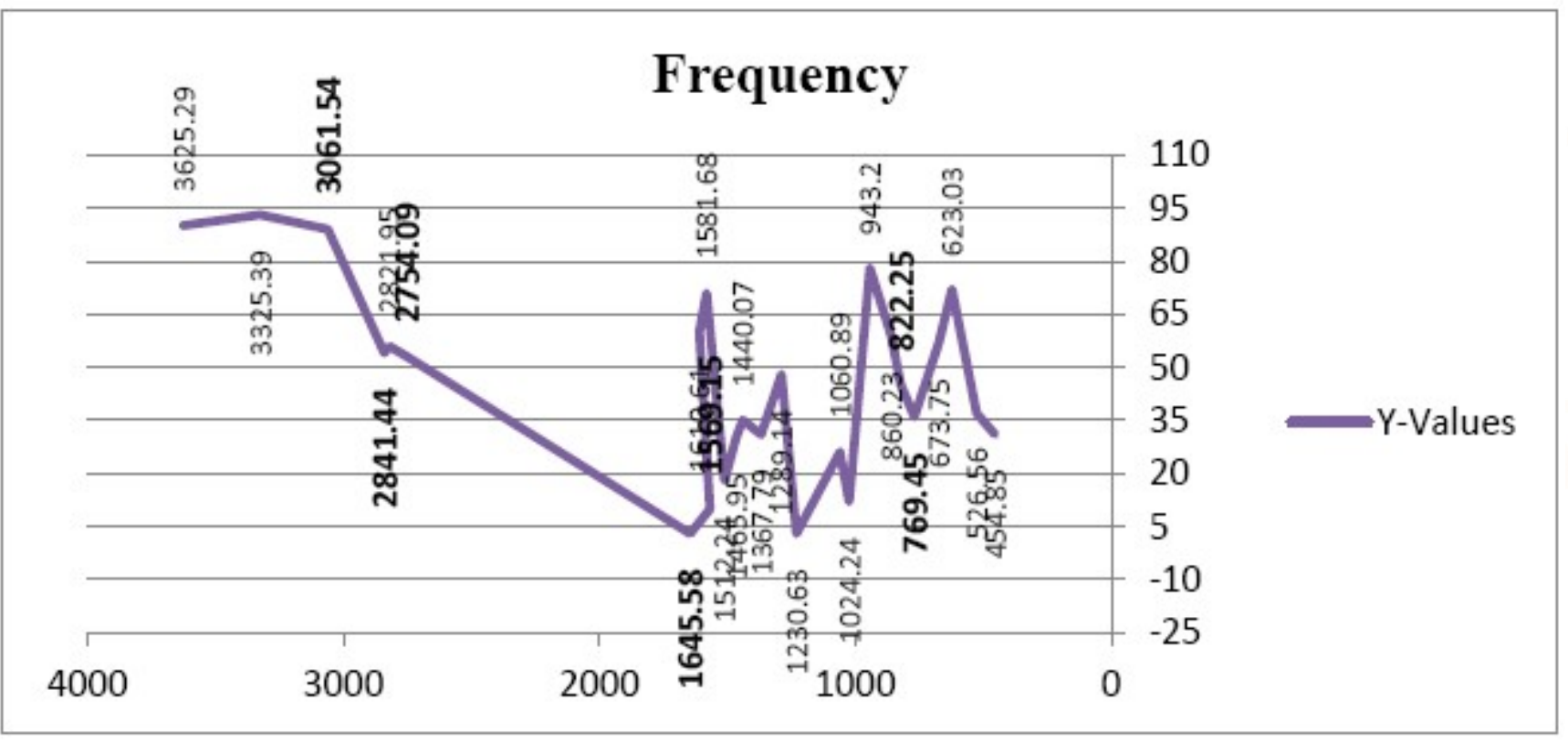


Table: FT-IR Spectral data of Propranolol

\begin{tabular}{|c|c|}
\hline Frequency $\left(\mathrm{cm}^{-1}\right)$ & Assignment \\
\hline 3061.54 & Aromatic C-H stretch \\
\hline 2841.44 & Aliphatic C-H stretch \\
\hline 2754.09 & O-CH${ }_{3}$ C-H stretch \\
\hline 1645.58 & Acetate $\mathrm{C}=$ O stretch \\
\hline 1569.15 & Lactam $\mathrm{C}=$ O stretch \\
\hline 822.25 & o-substituted aromatic C-H out of-plane deformation \\
\hline 769.45 & p-substituted aromatic C-H out of-plane deformation \\
\hline
\end{tabular}

\section{Differential Scanning calorimetry (DSC) analysis}

DSC enables the quantitative detection of all processes in which energy is required or produced. Pure powered Propranolol showed a melting endotherm at $158^{\circ} \mathrm{C}$. DSC study is useful for further drug excipients interaction study to check suitability of polymer ${ }^{6}$.

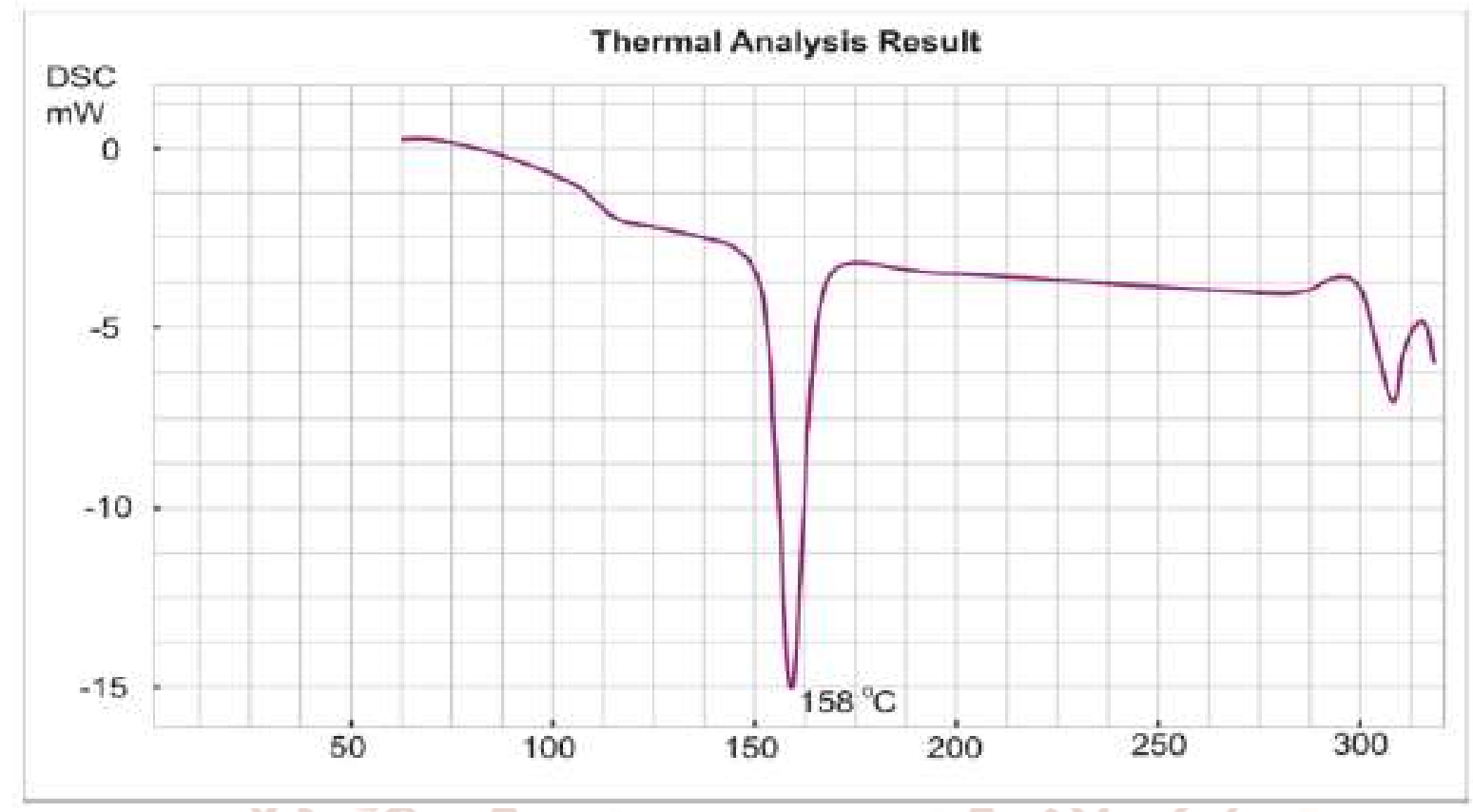

Figure: DSC thermogram of Propranolol

The monolithic transdermal patches of Propranolol hydrochloride using ethyl cellulose and polyvinyl pyrrolidone were prepared by solvent evaporation and solvent casting technique and were flexible, smooth and transparent.

$>$ Drug excipient interaction study:-

The transdermal patches were also evaluated for the physical parameters ${ }^{5,7}$ Table: Physical parameters and drug content of transdermal patches

\begin{tabular}{|c|c|c|c|c|c|c|c|c|}
\hline $\begin{array}{l}\text { Batch } \\
\text { codes }\end{array}$ & $\begin{array}{l}\text { Physical } \\
\text { appearance }\end{array}$ & $\begin{array}{l}\text { * Weight } \\
\text { (mg) }\end{array}$ & $\begin{array}{l}\text { *Thickness } \\
(\mathrm{mm})\end{array}$ & $\begin{array}{l}\text { *Drug } \\
\text { content }\end{array}$ & $\begin{array}{c}\text { *Surface } \\
\text { pH }\end{array}$ & $\begin{array}{l}\text { *Folding } \\
\text { endurance }\end{array}$ & $\begin{array}{l}\text { Flatness } \\
(\%)\end{array}$ & $\begin{array}{l}\% \text { Swellab } \\
\text { ility }\end{array}$ \\
\hline $\mathrm{F} 1$ & ++ & $\begin{array}{c}7.5 \pm \\
0.002\end{array}$ & $\begin{array}{c}0.169 \pm \\
0.001\end{array}$ & $\begin{array}{c}96.9 \pm \\
0.30\end{array}$ & $\begin{array}{l}6.2 \pm \\
0.15\end{array}$ & $289 \pm 0.52$ & 100 & 11.9 \\
\hline $\mathrm{F} 2$ & ++ & $\begin{array}{l}7.9 \pm \\
0.050\end{array}$ & $\begin{array}{c}0.172 \pm \\
0.001\end{array}$ & $\begin{array}{c}97.5 \pm \\
0.10\end{array}$ & $\begin{array}{l}6.9 \pm \\
0.10\end{array}$ & $296 \pm 0.01$ & 100 & 14.3 \\
\hline F3 & ++ & $\begin{array}{l}8.15 \pm \\
0.001\end{array}$ & $\begin{array}{c}0.170 \pm \\
0.005\end{array}$ & $\begin{array}{c}97.9 \pm \\
0.52\end{array}$ & $\begin{array}{l}6.2 \pm \\
0.11\end{array}$ & $295 \pm 0.57$ & 100 & 15.5 \\
\hline $\mathrm{F} 4$ & ++ & $\begin{array}{c}9.16 \pm \\
0.001\end{array}$ & $\begin{array}{c}0.172 \pm \\
0.007\end{array}$ & $\begin{array}{c}98.5 \pm \\
0.11\end{array}$ & $\begin{array}{l}6.8 \pm \\
0.10\end{array}$ & $297 \pm 0.15$ & 100 & 17.92 \\
\hline
\end{tabular}

++ Satisfactory; *Average of three determinations for each parameter 


\section{In vitro permeation studies:-}

The permeation study was carried out for 11 hours and maximum permeation was obtained for formulation F4 (97.42) and minimum permeation was obtained for formulation F1 (65.54). Formulation F1 contained higher proportion of Ethyl cellulose and it showed comparatively sustained release pattern. Hence for obtaining sustained release high concentration of ethyl cellulose is required ${ }^{5}$. The cumulative percentage of drug permeated for all the formulations have been shown in the plot of cumulative percent of drug permeated v/s time has been shown in Figure:

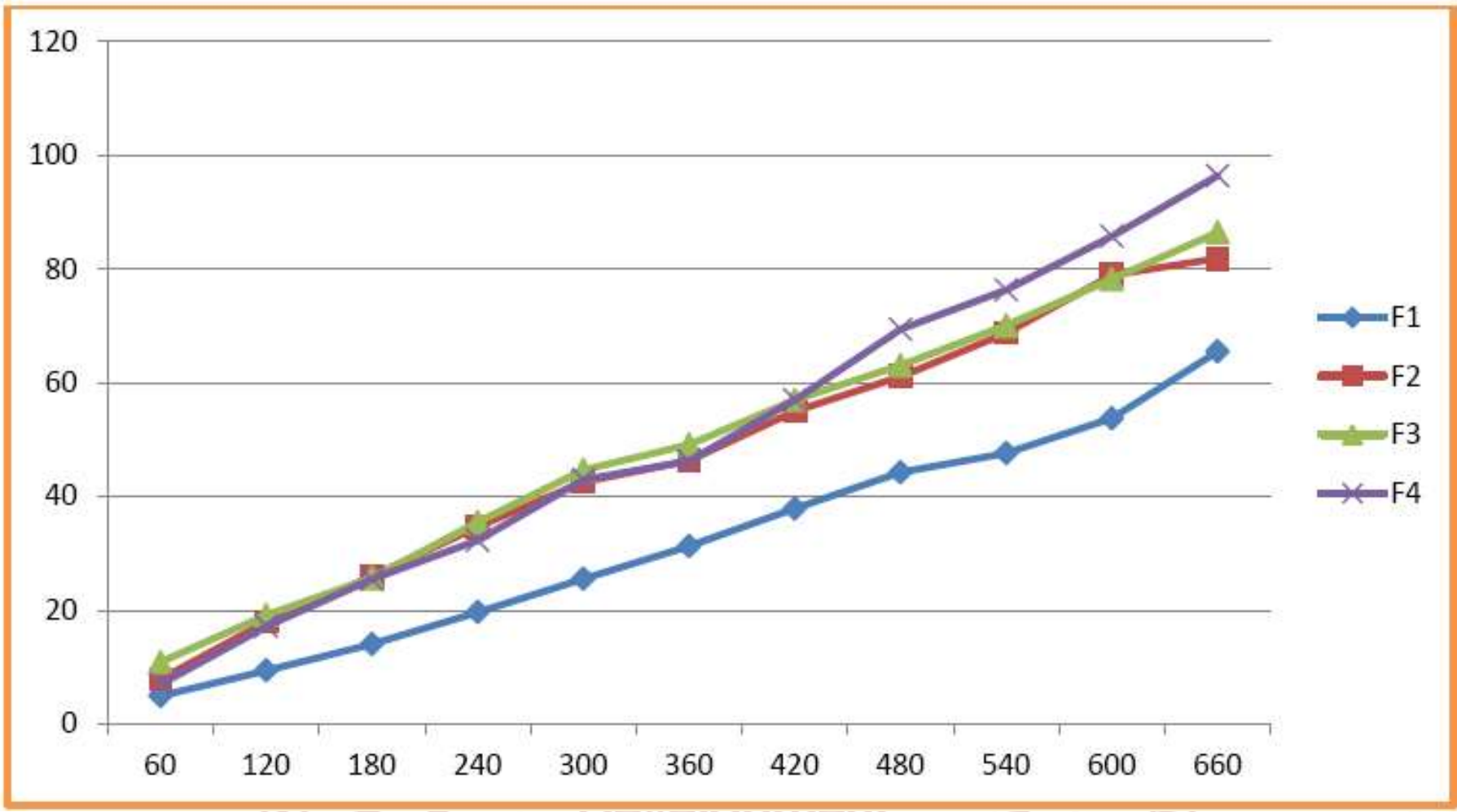

Fig: \% Cumulative drug permeated vs time (min) for the formulations $\mathrm{F} 1-\mathrm{F} 4$

\begin{tabular}{|c|c|c|c|c|}
\hline $\begin{array}{c}\text { Time } \\
(\text { min) }\end{array}$ & $\begin{array}{c}\text { Cumulative \% of } \\
\text { Drug permeated (F1) }\end{array}$ & $\begin{array}{c}\text { Cumulative \% of } \\
\text { Drug permeated (F2) }\end{array}$ & $\begin{array}{c}\text { Cumulative \% of } \\
\text { Drug permeated (F3) }\end{array}$ & $\begin{array}{c}\text { Cumulative \% of } \\
\text { Drug permeated (F4) }\end{array}$ \\
\hline 60 & 4.932 & 7.89 & 10.9 & 6.99 \\
\hline 120 & 9.415 & 17.99 & 19.2 & 17.2 \\
\hline 180 & 14.05 & 25.98 & 25.69 & 25.44 \\
\hline 240 & 19.69 & 34.7 & 35.53 & 32.28 \\
\hline 300 & 25.52 & 42.56 & 44.68 & 42.99 \\
\hline 360 & 31.28 & 46.32 & 49.15 & 46.23 \\
\hline 420 & 37.9 & 55.01 & 57.01 & 56.99 \\
\hline 480 & 44.25 & 61.12 & 63.09 & 69.42 \\
\hline 540 & 47.63 & 68.78 & 70.1 & 76.34 \\
\hline 600 & 53.76 & 78.95 & 78.23 & 85.78 \\
\hline 660 & 65.54 & 81.88 & 86.46 & 97.42 \\
\hline
\end{tabular}

\section{$>\quad$ Drug release kinetics:-}

The in vitro permeation data obtained for all the formulations was fitted to various kinetic models to elucidate the permeation profile. The drug permeation profile for all the formulations was found to follow zero order kinetics as evidenced by the straight line and higher regression value depicted in Figure. Thus the release rate was independent of the concentration of the drug. The kinetic models for various formulations have been shown in the table below ${ }^{5,7}$. 
International Journal of Trend in Scientific Research and Development (IJTSRD) ISSN: 2456-6470

Table: Value of $\mathrm{R}^{2}$ for different kinetic models for formulations F1-F4

\begin{tabular}{|c|c|c|c|c|c|}
\hline \multirow{2}{*}{$\begin{array}{c}\text { Formulation } \\
\text { Code }\end{array}$} & \multicolumn{5}{|c|}{$\mathbf{R}^{2}$} \\
\cline { 2 - 6 } & Zero order & First order & Higuchi & Korsemeyer Peppa's & n value \\
\hline F1 & 0.985 & 0.866 & 0.866 & 0.982 & 0.119 \\
\hline F2 & 0.989 & 0.921 & 0.921 & 0.982 & 0.109 \\
\hline F3 & 0.988 & 0.925 & 0.925 & 0.971 & 0.101 \\
\hline F4 & 0.990 & 0.889 & 0.889 & 0.955 & 0.699 \\
\hline
\end{tabular}

\section{CONCLUSION}

Propranolol base was prepared from its official hydrochloride salt and characterized using different parameters. Melting point was determined to check purity of drug. From solubility study it was found that $0.01 \mathrm{~N} \mathrm{HCl}$ was able to maintain sink condition, so it was suitable as a diffusion medium. The results obtained from Partition co-efficient study revealed that the drug possessed sufficient lipophillicity, which fulfills the requirements of formulating it into a transdermal patch. Differential scanning calorimetry and Fourier transform infrared spectroscopy gave idea regarding chemical structure of pure drug. UV/VIS Spectroscopic data are useful for the preparation of standard curve and estimation of Propranolol base released from various formulations.

Formulated patches were found to be smooth flexible and transparent and exhibited good physicochemical properties. The in vitro permeation study indicated increase in the permeation rate with the increase in the concentration of hydrophilic polymer and formulation F4 was found to depict maximum release as compared to other formulations. The release kinetics was found to follow zero order and non fickian diffusion. The results of evaluation studies indicated that the formulated patches of Propanolol hydrochloride shows better compliance than conventional drug delivery system. Studies have depicted promising results and it holds scope for further pharmacokinetic and pharmacodynamic evaluation to filter out the potential of this delivery system.

\section{REFERENCES}

1. Preeti Kush, Vivek Thakur, Parveen Kumar, "Formulation and In-Vitro Evaluation of Propranolol Hydrochloride Loaded Polycaprolactone Microspheres", Int. J. Pharm.
Sci. Rev. Res., 20(2), ISSN 0976 - 044X, May Jun 2013; n 48, 282-290.

2. Saxena A, Singh RK, Dwivedi A, Khan I, Singh A, Raghuvendra, Preparation and evaluation of microspheres of propranolol hydrochloride using eudragit RL as the matrix material, Am-Euras. J. Sci. Res. 6, 2, 2011, 58-63.

3. Martindale The Extra Pharmacopoeia, 31st ed., Reynolds, J. E. F., ed., Royal Pharmaceutical Society (London, GB: 1996), pp. 936-933. The Merck Index, 12th ed., Entry\# 8025.

4. Misra A.N., "Controlled and Novel Drug Delivery. In: N.K. Jain(Eds.), Transdermal Drug Delivery", New Delhi, India: CBS Publisher and Distributor. 1997. 100-101.

5. Rakesh P. Patel, Grishma Patel, Ashok Baria, "Formulation and evaluation of transdermal patch of Aceclofenac", International Journal of Drug Delivery 1(2009) 41-51.

6. Jamakandi V.G., Mulla J.S., Vinay B.L., "Formulation, characterization and evaluation of matrix type transdermal patches of a model antihypertensive drug", Asian J. Pharm., 1, 2015, 59-65.

7. V. N. L. Sirisha, P. Kirankumar, M. ChinnaEswaraiah, "Formulation and Evaluation of Transdermal Patches of Propranolol Hydrochloride", IOSR Journal of Pharmacy, ISSN: 2250-3013, Volume 2 Issue 5, Sep-Oct. 2012, PP.31-37.

8. Agrawal SS, Munjal P. Permeation studies of atenolol and metoprolol tartarate form three different polymer matrices for transdermal delivery. Ind J Pharm Sci. 2007: 535-9. 